\title{
К рождению современного украинского правописания
}

\author{
МИХАЙ КОЧИШ \\ Kocsis Mihály, SZTE BTK Szláv Intézet, H-6722 Szeged, Egyetem u. 2. \\ Institute of Slavic Philology, Faculty of Arts, University of Szeged \\ E-mail: kocsism@lit.u-szeged.hu
}

(Received: 11 January 2018; accepted: 7 February 2018)

\begin{abstract}
Modern Ukrainian orthography based on the phonetic principle was born in the 19th century: about 50 different orthographic systems were created by writers, ethnographers, linguists, and others. Some of these proposals, however, are not paid enough attention to in monographs. The present paper also claims that the scientists had to deal with two different groups of questions: the first set of issues was related to Ukrainian linguistic features, the other set was purely orthographic. Facts reveal that the solution to the first set of problems was much simpler. The final conclusion states that the re-evaluation of the 19th century in the history of the Ukrainian orthography is inevitable.
\end{abstract}

Keywords: Ukrainian language, history of orthography, 19th century, modern spelling

In тетогіат профессора В. В. Нимчука

Современное украинское правописание является, с общеизвестными отклонениями, в основном, фонетическим, таким образом, и его постепенное усовершенствование должно рассматриваться и оцениваться именно с этой позиции, а не с точки зрения меры формального совпадения использованных в предыдущих веках графических средств с теми, которые в употреблении сегодня.

Самым важным знаком действия фонетического принципа мы считаем однозначное соединение буквы только к одному определенному звуку (говоря о букве и звуке, мы имеем в виду, конечно, графему и фонему). На наш взгляд, соответствие буквы и звука не обязательно бывает взаимным, иначе говоря, передача одного и того же звука двумя разными буквами не выходит еще за пределы фонетического правописания, а только осложняет его. Такое понимание фонетического принципа будет весьма полезным для нас при оценке тех попыток создания украинского правописания, которые явно прослеживаются в первой половине XIX века.

Ученым и писателям того времени необходимо было решить ряд вопросов, которые можно разделить на две группы.

К первой группе принадлежало обозначение тех фонетических изменений, которые отличали украинский язык от русского. Самые главные из них: совпадение старых $y$ и $i$, продление $o$ и $e$ в новых закрытых слогах, своеобраз- 


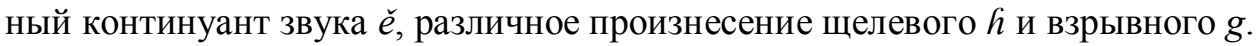
Последовательное обозначение этих т. н. украинизмов приводит к легко усваиваемому правописанию, а их игнорирование обеспечивает сохранение того огромного круга читателей художественной и научной литературы, в котором оказывались все, кто владел русским языком - вот дилемма, стоявшая перед писателями и учеными первой половины XIX века (об этом см. Kocsis 2013b: 222). И именно такая ситуация позволяет нам более свободное толкование фонетического принципа, как об этом говорилось выше.

Другая группа состояла из «чистых» орфографических проблем, часть которых возникла вследствие древних языковых изменений (и которые, почти без исключения, известны также и из истории русского правописания). К ней принадлежали: обозначение конца слова знаком ь или без него; передача звукосочетаний $j+e, j+o, j+i$, а также обозначение мягкости согласного перед гласными $e, o, i$ (т. е. применение т. н. йотированных букв - кроме беспроблемных я и ю); и еще - способ передачи звука $j$ в позиции после согласного.

Перечисленные выше проблемы не охватывают все вопросы, которыми занимались создатели современного украинского правописания, но они, повидимому, были самыми существенными. Об этом свидетельствует и таблица профессора Ивана Огиенко, составленная в начале XX века (ОгиЕнко 1919).

О таблице И. Огиенко хотелось бы сказать несколько слов. Во-первых, мы не изменили орфографию профессора. Во-вторых, его таблица в некоторых местах подверглась исправлению с привлечением тех примеров, которые были приведены самим профессором из названных им источников, и которые читаются под таблицей. В-третьих, мы применили сокращения $н$. и ніч. (у Огиенко: нема и нічого).

Таблища 1. Историческое развитие украинского правописания

\begin{tabular}{|c|c|c|c|c|c|c|c|c|c|c|c|}
\hline Автор & Рік & $\mathbf{b}$ & $\begin{array}{c}\text { Серед. } \\
\text { и }\end{array}$ & $\mathbf{i}<\mathbf{e}$ & $\mathbf{i}<\mathbf{0}$ & $\mathbf{i}<\mathbf{b}$ & $\ddot{\mathbf{i}}$ & $\mathbf{c}$ & йо, ьо & Глухі & $\mathbf{I}$ \\
\hline Стара & & $\mathbf{b}$ & ы, и & $\mathbf{C}$ & $\begin{array}{c}\mathbf{0}, \mathbf{n}, \\
\mathbf{b}\end{array}$ & $\mathbf{b}, \mathbf{u}$ & и & $\mathbf{E}, \boldsymbol{\epsilon}$ & io, î̂ & $\mathbf{b}, \mathbf{b}$, & $\mathbf{K \Gamma}, \mathbf{\Gamma}$ \\
\hline Котляревський & 1798 & $\mathbf{b}$ & ы, и & и & $\mathbf{u}, \mathbf{b}$ & $\mathbf{b}$ & b, и & $\mathbf{e}$ & io, $\mathbf{e}$ & & $\Gamma$ \\
\hline Котляревський & 1799 & $\mathbf{b}$ & Ы, и & и, B & и, B & b & И, B & $\mathbf{e}$ & io & b & \\
\hline Котляревський & 1809 & $\mathbf{b}$ & ы, и & и & $\mathbf{n}, \mathbf{b}$ & b, и & b, и & $\mathbf{e}$ & io & $\mathbf{b}$ & \\
\hline Павловський & 1818 & $\mathbf{b}$ & bI & $\mathbf{i}$ & i & i & $\mathbf{i}$ & b & io & $\mathbf{b}$ & кг \\
\hline Войцехович & 1823 & $\mathbf{b}$ & $\mathbf{U}, \mathbf{b}$ & $\mathbf{e}$ & $\mathbf{0}$ & $\mathbf{b}, \mathbf{u}$ & и & $\mathbf{e}$ & io & $\mathbf{b}$ & $\Gamma, \mathbf{K \Gamma}$ \\
\hline Могильницький & 1823 & $\mathbf{b}$ & Ы, и & e & $\mathbf{0}, \hat{\mathbf{o}}$ & $\mathbf{b}$ & и & $\mathbf{e}$ & & & $\Gamma$ \\
\hline Максимович & 1827 & $\mathbf{b}$ & и, ы & $\hat{\mathbf{e}}$ & $\hat{\mathbf{o}}$ & b & $\mathbf{n}, \hat{\mathbf{n}}$ & $\mathbf{e}$ & $\ddot{\mathbf{e}}$ & $\mathbf{b}$ & \\
\hline Лучкай & 1830 & H. & Ы & e & $\mathbf{0}$ & b & и, ї & $\mathbf{e}$ & & $\ddot{\mathbf{i}}$ & $\Gamma$ \\
\hline О. Левицький & 1834 & $\mathbf{b}$ & ы, и & & $\ddot{\mathbf{o}}, \hat{\mathbf{o}}$ & b & & $\mathbf{e}$ & $\ddot{\mathbf{e}}$ & & $\mathbf{I}$ \\
\hline $\begin{array}{c}\text { «Русалка } \\
\text { Дністрова» }\end{array}$ & 1837 & н. & и & i & $\mathbf{i}$ & b & $\mathbf{b}$ & $\mathbf{E}$ & йо, ьо & H. & \\
\hline
\end{tabular}




\begin{tabular}{|c|c|c|c|c|c|c|c|c|c|c|c|}
\hline Тополя & 1837 & $\mathbf{b}$ & ЫI & $\hat{\mathbf{u}}$ & $\hat{\mathbf{n}}$ & $\mathbf{b}, \hat{\mathbf{n}}$ & $\hat{\mathbf{u}}$ & e & iô & $\mathbf{b}$ & \\
\hline Писаревський & 1840 & $\mathbf{b}$ & ЫI & и & и & и & & $\mathbf{e}$ & ïo, io & $\mathbf{b}$ & кГ \\
\hline Карпенко & 1845 & $\mathbf{b}$ & Ы & и & и & и & іи, и & b & io & $\mathbf{b}$ & \\
\hline Вагилевич & 1845 & $\mathbf{b}$ & И, Ы & $\mathbf{e}$ & $\mathbf{0}$ & b & и & $\mathbf{e}$ & їо & H. & \\
\hline Глинський & 1845 & H. & и, Ы & b & $\ddot{\mathbf{0}}$ & b & $\mathbf{b}, \mathbf{i}$ & $\mathbf{E}$ & io & H. & $\mathbf{I}$ \\
\hline Лозинський & 1846 & H. & Ы, и & e & $\mathbf{0}$ & b, и & и & $\mathbf{e}$ & ьо, їо & $\mathbf{b}$ & $\mathbf{I}$ \\
\hline Головацький & 1849 & $\mathbf{b}$ & Ы, и & $\hat{\mathbf{e}}$ & $\hat{\mathbf{o}}$ & $\mathbf{b}$ & b & E & iô & $\mathbf{b}$ & $\mathbf{I}$ \\
\hline Основ'яненко & 1851 & $\mathbf{b}$ & и & $\mathbf{i}$ & i & i & и & $\mathbf{e}$ & $\ddot{\mathbf{e}}$ & $\mathbf{b}$ & \\
\hline Боровиковський & 1852 & H. & $\mathbf{v}, \mathbf{\text { I }}$ & и & и & и & и & E & $\ddot{\mathbf{e}}$ & & g \\
\hline Метлинський & 1854 & H. & ы & & & и & и & $\mathbf{c}, \mathbf{e}$ & йо, ьо & $\mathbf{b}$ & \\
\hline Куліш & 1856 & $\mathbf{b}$ & и & $\mathbf{i}$ & $\mathbf{i}$ & $\mathbf{i}$ & $\mathbf{i}$ & $\mathbf{c}, \mathbf{e}$ & $\ddot{\mathbf{e}}$ & $\mathbf{b}$ & \\
\hline Максимович & 1859 & $\mathbf{b}$ & Ы, и & $\hat{\mathbf{e}}$ & $\hat{\mathbf{o}}$ & b & $\hat{\mathbf{u}}$ & E & $\ddot{\text { ë }}$ & $\mathbf{b}, \mathbf{b}$ & \\
\hline Шевченко & 1861 & $\mathbf{b}$ & ЫI & и, i & и, i & и, i & и & $\mathbf{e}$ & $\ddot{\mathbf{e}}$ & H. & \\
\hline «Основа» & 1861 & $\mathbf{b}$ & и & $\mathbf{i}$ & $\mathbf{i}$ & i & $\mathbf{i}$ & $\mathbf{e}$ & $\ddot{\text { ë }}$ & $\mathbf{b}, \mathbf{b}$ & \\
\hline Куліш & 1861 & $\mathbf{b}$ & и & $\mathbf{i}$ & $\mathbf{i}$ & $\mathbf{i}$ & $\mathbf{i}$ & $\mathbf{e}, \mathbf{c}$ & $\ddot{\text { ë }}$ & ніч. & g \\
\hline Гаццук & 1861 & H. & и & $\ddot{\mathbf{i}}$ & $\ddot{\mathbf{i}}$ & $\ddot{\mathbf{i}}$ & i & 'є, $\mathbf{\epsilon}$ & $\hat{\mathbf{o}}$ & , & \\
\hline Осадца & 1862 & $\mathbf{b}$ & Ы, и & e, $\mathbf{b}$ & $\hat{\mathbf{o}}$ & b & и & $\boldsymbol{E}$ & io & $\mathbf{b}$ & \\
\hline Номис & 1864 & H. & и & i & $\overline{\mathbf{i}}$ & $\mathbf{i}$ & i & $\mathbf{C}$ & $\ddot{\text { ë }}$ & $\mathbf{b}$ & $\mathrm{g}$ \\
\hline Дячан & 1865 & $\mathbf{b}$ & Ы, и & $\hat{\mathbf{e}}$ & $\hat{\mathbf{o}}$ & b & & E & & & \\
\hline «Записки» & 1873 & H. & и & i & $\mathbf{i}$ & $\mathbf{i}$ & $\ddot{\mathbf{i}}$ & E & bo, ë & & кГ \\
\hline Рудченко & 1874 & H. & и & $\mathbf{i}$ & $\mathbf{i}$ & i & $\ddot{\mathbf{i}}$ & $\mathbf{E}$ & $\ddot{\mathbf{e}}$ & $\mathbf{b}$ & \\
\hline Чубинський & 1874 & $\mathbf{b}$ & и & $\mathbf{i}$ & $\mathbf{i}$ & $\mathbf{i}$ & $\mathbf{i}$ & E & $\ddot{\text { ë }}$ & $\mathbf{b}$ & \\
\hline Антонович & 1874 & H. & и & $\mathbf{i}$ & i & i & $\ddot{\mathbf{i}}$ & E & $\ddot{\text { ë }}$ & $\mathbf{b}, \mathbf{b}$ & \\
\hline Комаров & 1874 & н. & и & i & i & i & $\ddot{\mathbf{i}}$ & $\mathbf{E}$ & $\ddot{\mathbf{e}}$ & $\mathbf{b}$ & \\
\hline Лобода & 1874 & н. & и & $\mathbf{i}$ & i & i & йi & $\mathbf{E}$ & йо, ьо & $\mathbf{b}$ & $\mathbf{g}$ \\
\hline Костомаров & 1875 & $\mathbf{b}$ & и & $\mathbf{i}$ & i & i & $\mathbf{i}$ & $\mathbf{e}$ & $\ddot{\text { ë, io }}$ & $\mathbf{b}, \mathbf{b}$ & \\
\hline Драгоманов & 1876 & H. & и & $\mathbf{i}$ & $\mathbf{i}$ & $\mathbf{i}$ & $\ddot{\mathbf{i}}$ & $\mathbf{E}$ & $\ddot{\mathbf{e}}$ & & \\
\hline Старицький & 1876 & $\mathrm{H}$. & и & i & i & i & $\ddot{\mathbf{i}}$ & $\mathbf{E}$ & $\ddot{\mathbf{e}}$ & $\mathbf{b}, \mathbf{b}$ & \\
\hline $\begin{array}{c}\text { «Кобзар» } \\
\text { (Прага) }\end{array}$ & 1876 & H. & и & $\mathbf{i}$ & $\mathbf{i}$ & $\bar{i}$ & $\ddot{\mathbf{i}}$ & E & $\ddot{\text { ë }}$ & $\mathbf{b}, \mathbf{b}$ & \\
\hline Ніщинський & 1883 & $\mathbf{b}$ & и & $\mathbf{i}$ & i & i & i & $\mathbf{e}$ & $\mathbf{e}$ & & \\
\hline «Рада» & 1883 & $\mathbf{b}$ & и & i & $\mathbf{i}$ & $\mathbf{i}$ & $\mathbf{i}$ & $\mathbf{e}$ & $\ddot{\mathbf{e}}$ & $\mathbf{b}$ & \\
\hline Огоновський & 1889 & $\mathbf{b}$ & Ы, и & $\hat{\mathbf{e}}, \mathbf{b}$ & $\hat{\mathbf{o}}$ & b & и & $\mathbf{E}$ & & & \\
\hline Желехівський & 1889 & H. & и & $\ddot{\mathbf{i}}$ & i & $\ddot{i}$ & $\ddot{\mathbf{i}}$ & E & йо, ьо & ніч. & \\
\hline $\begin{array}{c}\text { «Громадська } \\
\text { Думка» }\end{array}$ & 1905 & H. & и & $\mathbf{i}$ & $\mathbf{i}$ & $\mathbf{i}$ & $\ddot{\mathbf{i}}$ & $\mathbf{c}$ & йо, ьо & , & $\mathbf{r}$ \\
\hline Тепер & 1918 & н. & $\mathbf{и}$ & $\mathbf{i}$ & i & i & $\ddot{\mathbf{i}}$ & E & йо, ьо & ', $\mathbf{b}$ & $\mathbf{r}$ \\
\hline
\end{tabular}

Таким образом, исходным пунктом наших наблюдений станет данная таблица, хотя она не является полной. В ней отсутствуют и некоторые такие труды, которые мы считаем важными: 1) четвертое издание «Энеиды» И. Котляревского от 1842 г., ${ }^{1}$ 2) «Южный русский зборник» А. Метлинского от 1848 г., ${ }^{2}$ 3) уникальная система М. Драгоманова от 1877 г. ${ }^{3}$ 
А теперь приступим к отдельному рассмотрению тех проблем, о которых речь шла в начале статьи.

1. Своеобразный (передне-средний) украинский гласный $y$ (IPA: 1) возник слиянием двух более ранних звуков - древнерусских $y$ и $i$. Его передача отвечает точному отражению украинской звуковой системы в том случае, если она происходит с помощью такой буквы, которой другой звук не обозначается. Данное требование впервые осуществляется в грамматике А. Павловского (1818 г.) только написанием буквы ы (правда, после г, к, х и он писал и - см. Нгмчук 2004: 7). Уже второстепенное значение имеет выбор графемы и, эксклюзивное употребление которой раньше всего наблюдается в «Русалке Днестровой» (1837 г.). Окончательной победа буквы и (над ы) становится только с 1860-х гг.

2. Древние $о$ и $е$ в новых закрытых слогах подверглись продлению, которое в литературном языке передается как $i$. Данное изменение отражается уже у И. Котляревского, но хотим заметить, что первые два неполных издания «Энеиды» (1798 г., 1799 г.) вышли без ведома и разрешения автора, следовательно, мы имеем право говорить о его правописании лишь начиная с третьего издания поэмы (1809 г.). С точки зрения фонетического правописания третье издание является несовершенным не по той причине, что звук $i$ передается двумя буквами (т. е. через и и $\mathbf{b}$ ), а скорее потому, что первая из них и обозначает и другой звук $y$ (т. н. украинский). В отличие от Котляревского, способы передачи звуков $y$ (украинского) и $i$ не совпадают у А. Павловского (1818 г.), который для обозначения последнего впервые употребил букву і. За Павловским следуют «Русалка Днестровая» (1837 г.), Г. КвиткаОсновьяненко (1851 г.) и П. Кулиш (1856 г.), а затем, начиная с 1860-х гг., употребление этой графемы становится общераспространенным. Также хотим отметить, что с точки зрения фонетического принципа безупречной является попытка и М. Максимовича (1827 г.) передать $i$ буквами е̂ и о̂, т. к. произношение тут обозначается, на самом деле, «крышкой», а буква под ней подсказывает нам происхождение звука (об этом подробнее см. Kocsis 2011,

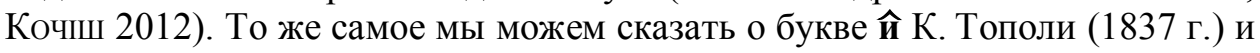
о графеме и С. Писаревского (1840 г.) - у обоих писателей данные буквы отличаются от графемы украинского $y$. Последователем Максимовича будет Я. Головацкий (1849 г.), а Писаревского - С. Карпенко (1845 г.). В отсутствующем в таблице профессора Огиенко четвертом издании «Энеиды» (1842 г.) Котляревский звук $i$ передает графемой и, а $y$ - буквой ы (см. ниже примечание 1; о Котляревском еще см. Кочиш 2012). В сборнике 1848 г. А. Метлинского, о котором Огиенко также умалчивает, на месте закрытых $o$ и $e-$ подобно К. Тополе - читается $\hat{\mathbf{n}}$, а для передачи украинского $y-\mathbf{u}$ (см. примеры дзвйн, весйльля, но милий, дитина, одним - МЕТлинский 1848: 25).

3. В говорах, лежащих в основе современного литературного языка, произнесение звука е̌ (ять) уже веками было $i$, следовательно, передача звука $i$ буквой $\mathbf{b}$ в полной мере отвечает современной звуковой системе. И. Котляревский в 1809 г. употребил графемы в и и для обозначения звука $i$ - проис- 
ходившего и от $\check{е}$, и от $о$ закрытого слога, однако буквой и передавался также украинский $y$. (Таким образом, данная система еще не была чисто фонетической.) В четвертом издании «Энеиды» (1842 г.), помимо передачи $i$ любого происхождения через и, на месте звука $y$ писалась отличающаяся от нее буква ы - а это уже безупречное фонетическое правописание (Kocsis 2013a: 290). Писать букву і на месте е̌ предложил А. Павловский, но из этого не следует, что правописание М. Максимовича, сохранившее ъ, не было полностью фонетическим. (Нельзя забывать о том, что «крышка» была обязательной у него только над о и е, но старый $\check{e}$ во всех позициях перешел в $i$, что сделало излишним добавление диакритического знака.) Исходя из этого, совершенно фонетической можно считать также более сложную систему «Русалки Днестровой» 1837 г. (с сохранением написания $\mathbf{b}$, но с буквой $\mathbf{i}$ на месте закрытых $o, e)$ и простейшую систему С. Писаревского 1840 г. (и для передачи $i$ любого происхождения) - ведь украинский у в обоих правописаниях передается не этими буквами.

4. В грамотах Средневековья взрывной $g$ часто обозначался диграфемой кг, а, начиная с грамматики 1619 г. Мелетия Смотрицкого, и буквой г (ПАночко 1993: 214-215). На протяжении XIX века этот звук передавался разными способами: кг (А. Павловский 1818 г., С. Писаревский 1840 г., «Записки» 1873 г.), г (О. Левицкий 1834 г., Т. Глынский 1845 г., И. Лозинский 1846 г., Я. Головацкий 1849 г.), и даже латинской g (Л. Боровиковский 1852 г., П. Кулиш 1861 г., М. Номис 1864 г., М. Лобода 1874 г.). Мы хотим заметить, что, с одной стороны, употребление графемы для передачи взрывного согласного касалось небольшого количества слов, и, с другой - выбор буквы мог зависеть и от возможностей данной типографии, как это предполагается и по отношению к грамматике А. Павловского (Нгмчук 2004: 7).

5. Обозначение конца слова знаком в (или, без него, лишь интервалом), представляет собой чисто орфографическую проблему, не имеющую никакого значения с точки зрения прочтения текста. Если мягкость концевого согласного передается мягким знаком, то его пропуск в конце слова сам по себе будет указывать на твердый звук, т. е. написание ь оказывается просто излишним. Впервые в истории украинского правописания концевой твердый знак перестали употреблять М. Лучкай (1830 г.) и редакторы «Русалки Днестровой» (1837 г. - об этом см. еще Кочाш 2015), но маргинальный характер данной орфографической проблемы оправдывается и тем фактом, что у многих твердый знак был в употреблении уже и в 1880-е гг.

6. Что же касается применения т. н. йотированных букв, в связи с их употреблением возникает лишь одно, но новое и обязательное требование. Какова бы ни была форма нейотированного гласного, графическое изображение его йотированной пары должно отличаться от нее.

Раньше всего буква с для передачи звукосочетания $j+e$ читается в «Русалке Днестровой» (1837 г.), однако только с 1860-х гг. ее постоянное употребление становится всеобщим. В первой половине XIX века-следуя за русской графикой - самым распространенным является написание е, но есть не- 
которые из ученых и писателей (А. Павловский 1818 г., С. Карпенко 1845 г.), которые этой графеме предпочитают букву §. Два этих способа передачи $j+e$ (через е или в) обладают неодинаковой ценностью: графемой е передаются и гласный $e$, и $j+e$, что приводит к нарушению фонетического принципа, но наблюдаемая у А. Павловского и С. Карпенко графема $\mathbf{b}$ для передачи другого звука не употребляется.

Следуя этой логике, для обозначения звукосочетания $j+o$ (и гласного 'o после мягкого согласного) применение «русской» ё или же современной группы букв йо, ьо являются одинаково совершенными. Таким образом, неслучайно, что ё выходит из употребления лишь в самом конце XIX века, несмотря на то, что группы йо, ьо известны уже с «Русалки Днестровой» (1837 г.).

Самой молодой буквой современной украинской азбуки является ї. Она появилась в 1873 году в «Записках» (полное название журнала: «Записки Юго-западнаго отдъла Императорскаго Русскаго географическаго общества»). Отличить графему $j+i$ от буквы звука $i$ (иногда даже и звука $y$ ) раньше не считалось важным. Исключение представляет собой система М. Гатцука $(1861$ г.), в которой $j+i$ обозначается графемой $\mathbf{i}$, а звук $i$ любого происхождения-ї.

К истории буквы ї мы добавим еще два примечания. Первое: эта буква встречается уже у М. Лучкая (1830 г.), но цель ее написания совершенно другая (например, бїю). Второе: хотя ї в правописании Е. Желеховского (1889 г.) употребляется часто (она пишется также на месте $е$ закрытого слога и е̌), мы должны учитывать то обстоятельство, что данная система разработана для галицких и буковинских школ. В здешних говорах согласный перед $i$ (из $o$ ) остается твердым (см. примеры [стіл], [сік] - Пгвторак 2018, а также НІмчук 2004: 10), а так как у Желеховского для передачи этого звука уже занята графема $\mathbf{i}$, он и передает тот $i$, перед которым согласный смягчается - йотированной буквой ї. Значит, Желеховский в этом отношении дополняет уже существующий ряд $\mathbf{a}-\boldsymbol{я}, \mathbf{y}-\mathbf{ю}, \mathbf{e}-\mathbf{c}$ новой парой $\mathbf{i}-\mathbf{i}$, у которых первый компонент стоит всегда после твердого согласного, а второй - после мягкого.

7. Произнесение звука $j$ внутри слова после согласного обозначалось поразному: с помощью мягкого или твердого знака, апострофа или никак. Так как эта проблема относится к вопросам сугубо правописания, то читаемые предложения или следовали русской орфографии, или отличались от нее.

Подведем итоги.

1. Данные показывают, что при формировании современного фонетического правописания те проблемы, которые были связаны с т. н. украинизмами, решились значительно раньше, чем другие, исключительно орфографические вопросы.

2. Совершенствование фонетического правописания отождествляется не с более полным совпадением прежних и сегодняшних графем, а представляет собой все более и более однозначное соответствие букв к определенным звукам. 
3. Принимая во внимание такое понимание фонетического принципа, можем предположить, что современное украинское правописание на основе достижений преимущественно А. Павловского (1818 г.), М. Максимовича (1827 г.) и «Русалки Днестровой» (1837 г.) уже было разработано в 1840 -е гг. в Харькове, см. С. Писаревский (1840 г.), И. Котляревский (1842 г.), А. Метлинский (1848 г.) (об этом подробнее см. Kocsis 2013a).

4. Абсолютно фонетической является орфография Драгоманова 1877 г., которая является эпизодической в украинской письменности.

Наши предположения были высказаны на основе составленной профессором И. Огиенко таблицы об историческом развитии украинского правописания XIX века. Сопоставив имеющиеся в ней данные с текстом доступныХ оригинальных источников (некоторые из них уже можно прочитать на страницах Интернета), мы пришли к заключениям, что рассмотрение и оценка такого широкого (и во временном, и в пространственном отношении) материала сопровождается целым рядом трудностей.

Некоторые из них мы перечислим ниже:

1) В грамматиках первой половины XIX века, вышедших на разных (латинском, немецком, польском) языках, примеры, т. е. украинские слова, могут быть набраны полууставом (т. е. церковным шрифтом), что обязательно надо учитывать при их сопоставлении с примерами, взятыми из трудов, написанных гражданкой (например, полууставной букве в в гражданке будет соответствовать е). Часть расхождений между данными таблицы И. Огиенко и примерами, приведенными им под таблицей и всегда только гражданкой, объясняется этим фактом.

2) В фольклорных сборниках, содержащих материалы с разных мест украинского языкового ареала, ученые стремились к сохранению и диалектных особенностей, а это привело к разным способам передачи одного и того же звука языка, который считался и считается литературным. В подобных случаях мы имеем дело не с колебанием в передаче данного украинизма, а, наоборот, с точным обозначением диалектизмов.

3) В XIX веке украинские земли принадлежали не одному и тому же государству. Подробности отдельных грамматик могли зависеть и от языковых особенностей территории, для которой они (грамматики) были составлены. Например, система, разработанная Е. Желеховским, должна рассматриваться только с этой точки зрения (как об этом уже говорилось выше).

Но несмотря на все эти, а, может быть, и многие другие трудности, которые предстанут перед будущими исследователями, мы убеждены, что период рождения современного украинского правописания, т. е. его история в XIX веке, нуждается в фундаментальной переоценке.

К этому побуждают нас и слова профессора В. В. Нимчука о значении правописания П. Кулиша: «Розглянутий правопис дістав назву „кулішівка“. Він дуже відрізняється від сучасного украйнського правопису, і тому твердження А. Кримського, ніби „ми тепер пишемо кулішівкою“, - явна гіперболізація» (НІмчук 2004: 9). 


\section{Примечания}

${ }^{1}$ Между правописаниями третьего и четвертого (посмертного) изданий «Энеиды», которые были подготовлены к печати уже самим автором (об истории всех изданий см. ШАБЛІОВСьКИй-ДЕРКАч 1980: 5-8), налицо значительные расхождения. Чтобы показать различия между последними двумя изданиями, мы из третьего цитируем последнюю строфу второй части (со с. 26) на основе фотоснимка, который встречается в мировой сети (https:/ic.pics.livejournal.com/viktorshestakov/60120010/ 138146/138146_900.jpg), а рядом - ее вариант 1842 г. (КотляРЕВСКий 1842/II: 42):

Но видно вже пану Тарасу

Написано такъ на роду,

Щобъ тилько до сіого винъ часу

Терпћвъ на свђть семъ бъду.

Бо росхитавшись, бризнувъ въ воду,

Нырнувъ - и не спытавши броду,

На ввыринки пишла душа.

Эней хотъвъ, щобъ окошилась

Бъда и билшъ не продолжилась,

Щобъ не пропали всь съ коша.
Но выдно що пану Тарасу

Напысано такъ на роду,

Щобъ тилько до сього винъ часу

Терпивъ на свити симъ биду.

Бо розхытавшысь, брызнувъ въ воду, Нырнувъ - и не спытавшы броду,

Наввырынкы пишла душа.

Эней хотивъ, щобъ окошылась

Бида и билшъ не продолжылась,

Щобъ не пропалы вси съ коша.

2 В современных научных трудах последних десятилетий имя Амвросия Лукьяновича Метлинского (1814-1870) упоминается очень редко. Поэт, этнограф, профессор харьковского, а затем киевского университета полностью отсутствует в хрестоматии украинского правописания (НІмчук 2004): в введении, т. е. в историческом обзоре о нем не говорится, его не цитируют и не ссылаются на его труды в той части книги, где дается описание и разбор научных достижений важнейших ученых XIX века, он даже не включен в указатель имен в конце хрестоматии. Иван Франко, однако, высоко оценивает творчество А. Метлинского: «Як бачимо, Метлинський, ідучи за слідами Котляревського, Бодянського, Срезневського і авторів „Молодика“, був переконаний, що винайшов правопись середню між етимологією і фонетикою, а тим часом що ж він зробив? Викинув $\mathbf{b}, \mathbf{b}, \mathbf{b}$, заступив корінне о та е новою буквою $\hat{\mathbf{n}}$, викидаючи натомість $\mathbf{i}$, котрим Куліш заступив $\hat{\mathbf{n}}$; таким способом „середня“ правопись Метлинського була майже чисто фонетичною» (ФРАнко 1961: 29). Как мы видим, Франко, на самом деле, утверждает то, что главная роль П. Кулиша в истории украинского правописания - замена графемы $\hat{\mathbf{n}}$ буквой $\mathbf{i}$.

Приводим несколько строк из «Южного русского сборника» А. Метлинского (см. МЕтлинский 1848: 25):

Из неба па̀-свит гульк свята недиля, -

И зрадувавсь, повеселишав свит,

И вийшло сонечко мов на весйльля,

Из саду Божого мов милий квит.

Чиє-сь мале край церкви плаче тихо:

Чи-то воно вже знає лихо? (Сиритка)

${ }^{3}$ Разработанная к 1877 г. новая орфография Михаила Драгоманова, по отношению к используемой им же самим старой, оказалась радикально измененной. Она названа по имени ее создателя «драгомановкой». 
Драгомановка не знает йотированных букв. Предполагается, что под влиянием сербской орфографии, вместо букв я, ю,, , ё, ї пишется сочетание латинской буквы ј и буквы последующего гласного (jaмa, мојy, даје и т. п.). Мягкость согласных передана всегда (не только в конце слова) мягким знаком (земльа, прьамо, синье). Латинская ј употреблялась и в позиции конца слога (кајдани), а также после губных согласных, которые в украинском языке не смягчаются (мјасо) - сегодня данное явление на письме обозначается апострофом. Вместо одной буквы щ пишутся две: ш и ч, как это наблюдается и сегодня в современном белорусском правописании (иче) (ОгІєнко 2001: XVIII/14).

Драгомановка - единственная орфографическая система, в которой каждому звуку (точнее, каждой фонеме) соответствует по одной букве, и каждая буква обозначает по одному звуку (по одной фонеме). Исключение представляет собой передача на письме мягких согласных с помощью добавления мягкого знака (но нельзя забывать и о том, что в украинском языке, в отличие от сербского, существует ряд мягких согласных как самостоятельных фонем).

По мнению академика Агатангела Крымского, это новое правописание Драгоманова является не только радикально новым, но, с точки зрения научности, оно представляет собой наилучшее современное украинское правописание (Кримський 2004: 408), которое не получило достойное место в истории украинской орфографии, так как драгомановку приняли лишь те, кто был сторонником политических идей ее радикального создателя (НІмчук 2004: 9-10). Консервативные круги отказались от новизны правописания не только из-за того, что она была радикальной, но скорее всего по той причине, что эта новизна исходила именно от - жившего в эмиграции Михаила Драгоманова (Кримський 2004: 409). Весьма характерно, что́ сам ученый пишет о своей орфографии в письме к Ивану Франку от 11 июля 1887 г.: «Фонетична правопись, це полегкість всьакіј дитині, вивчитись читати ј писати, всьакому мужикові раз на завше задержати собі в голові ортографіју, не бојатись граматичних помилок, обходитись без писарьа і т. и.! Хиба ж це не револьуціја, навіть не „анархіја“ дльа певного сорту льудеј?» (ДРАГОмАнов 1908: 383).

\section{Литература}

ДРАГОМАНОВ 1908 = ДРАГОМАНОВ М. Листи до Ів. Франка і иниих (1887-1895). Львів, 1908.

КотляреВСКий 1842 = Виргиліева «Энеида», на малороссійскій языкъ переложенная И. Котляревскимъ I-VI. Харьковъ, 1842. [Факсимильное издание: Київ, 1979.]

Кочиш 2012 = Кочиш М. О правописании И. Котляревского и определении его места в истории украинской графики и орфографии. Slavica XLI. Debrecen, 2012. $107-110$.

Кочाш 2012 = Кочшш М. Михайло Максимович: етимологіст чи фонетик? HungaroRuthenica VI. Szeged, 2012. 93-96.

Кочाш 2015 = Кочाш М. Місто, де поховали $\epsilon p$. Hungaro-Ruthenica VII. Szeged, 2015. $115-118$.

Кримський 2004 = КРимський А. Нарис історії українського правопису до 1927 року. В кн.: Нгмчук В. В., ПуряевА Н. В. (упор.) Iсторія українського правопису XVIХХ століття. Хрестоматія. Київ, 2004. 392-414.

МЕтлинский 1848 = Южный русскій сборникъ, изданіе Амвросія Метлинскаго. Харьковъ, 1848. 
Нгмчук 2004 = Нгмчук В. В. Переднє слово. В кн.: Нгмчук В. В., ПуряеВА Н. В. (упор.) Історія українського правопису XVI-XX століття. Хрестоматія. Київ, 2004. 5-26.

ОгиЕнко 1919 = ОгиЕнко И. Таблиця історичного розвитку українського правопису. В кн.: ОГИЕнкО И. Курс украинского языка. Из лекций по истории украинского языка. Киев, 1919. http://litopys.org.ua/ukrmova/um81.htm.

ОгІєнко 2001 = ОгІєнко І. Історія украӥнськоӥ літературної мови. Київ, 2001. [Перше видання: Вінніпег, 1949.] Ч. 3. Гл. 18. П. 7. Правопис за І. Котляревського. http:// www.litopys.org.ua/ohukr/ohu20.htm.

ПАночко 1993 = ПАночко М. Літера «Г» в українській мові і укладання довідника слів з названою літерою. В кн.: Другий міжнародний конгрес україністів. Доповіді і повідомлення. Мовознавство. Львів, 1993. 214-217.

ПівтоРАК 2018 = ПІвтоРАК Г. П. Реформи алфавіту і графіки. Українська мова. Енцикллопедія. http://litopys.org.ua/ukrmova/um81.htm.

ФрАнко 1961 = ФрАнко І. Етимологія і фонетика в южноруській літературі. В кн.: Тимошенко П. Д. (упор.) Хрестоматія матеріалів з історії української літерамурної мови. Ч. 2. Київ, 1961. 22-37.

ШАБЛІОВСьКИЙ-ДЕРКАЧ 1980 = ШАБЛІОВСьКИЙ С. С., ДЕРКАЧ Б. А. Перлина української літератури. Передмова до факсимільного видання «Енеїди» 1842 р. Київ, 1980.

Kocsis 2011 = Kocsis Mihály: Mychajlo Maksymovyč helyesírásáról [О правописании Михаила Максимовича]. Studia Slavica Savariensia 2011/1-2: 177-179.

Kocsis 2013a = Kocsis Mihály: Harkov és az ukrán helyesírás-történet [Харьков и история украинского правописания]. Studia Slavica Savariensia 2013/1-2: 286-293.

Kocsis 2013b = Kocsis Mihály: „Oroszbarát” és „,szakadár” jelenségek az ukrán helyesírás történetében [«Русофильство» и «сепаратизм» в истории украинского правописания]. In: Tóтн Szergej (szerk.): Társadalmi változások-nyelvi változások. Alkalmazott nyelvészeti kutatások a Kárpát-medencében. (MANYE 9.) Budapest-Szeged, 2013. 221-223. 